\title{
Modeling the Impacts of Income on the Subjective Happiness: An Empirical Study
}

\author{
Guiping Ma $(i)$ and Changsong Ma \\ International College, Krirk University, Bangkok 10220, Thailand \\ Correspondence should be addressed to Changsong Ma; 13696017768@163.com
}

Received 16 August 2021; Accepted 27 September 2021; Published 14 October 2021

Academic Editor: Daqing Gong

Copyright (C) 2021 Guiping Ma and Changsong Ma. This is an open access article distributed under the Creative Commons Attribution License, which permits unrestricted use, distribution, and reproduction in any medium, provided the original work is properly cited.

\begin{abstract}
The influence of income on the subjective happiness of teachers in Chinese private universities is researched in this paper. First of all, considering the features of the Chinese private university, the measuring model of the subjective happiness of teachers in higher institutions was established. Then, the private university teachers in China were taken as investigation objects to collect data samples. Finally, based on the questionnaire data, the author will verify the measuring model by using the structural equation model. The empirical research results show that the welfare system of the investor has a positive impact on the teacher income, and the income has a notable positive impact on the subjective happiness of teachers through consumption level and housing conditions. Therefore, it has a significant positive influence on the subjective happiness of the teachers in Chinese private colleges. With the higher income, the subjective happiness of the teachers becomes stronger. In addition, the welfare system of the investor will also have a positive influence on the subjective happiness of the teachers through expenditure system, management culture, and enterprise welfare.
\end{abstract}

\section{Introduction}

With the development of the higher education in China, Chinese universities are increasingly diversified. The statistical data from the National Bureau of Statistics of China show that there are 756 private universities and 339,777 teachers here in 2019 , accounting for $28.125 \%$ of the total Chinese universities as shown in Figure 1 and $19.53 \%$ of all Chinese college teachers as shown in Figure 2, respectively. Those figures prove the key roles of private universities and private university teachers in Chinese higher education.

People long for happiness in their daily life and work. As happiness is hard to be definite, so does subjective happiness. There are various opinions about subjective happiness. Campbell et al. [1] believed that the subjective happiness refers to the overall happiness of people to life. However, the author [2] deemed that the subjective happiness refers to how people evaluate their life based on their standards. Li [3] thought that subjective happiness is a key and comprehensive psychological indicator to evaluate people's life.
Subjective happiness will have a greater impact on the life and work. Chen et al. [4] believed that subjective happiness will increase people's body mass index. The degree of influence varies with different factors. Happiness will affect people's nonprofessional qualities as well. Ogedengbe [5] believed that teachers' soft skills have a positive effect on the revival of education courses. Ju and Jung [6] found that experience satisfaction has a significant impact on intention of experience purchase in exhibition. Suldo et al. [7] conducted a research study on the subjective happiness of the children, and the findings are that primary school students can obtain evidence from the common active intervention aimed at internal assets (gratitude and kind) and signature advantage and environmental resources (student, teachers, and companion relationship). Income differences will not just have an important impact on the macro economy. Research studies by Florin Georgescu et al. [8] found that fiscal and income incentives cause imbalances in some functional market economies, economic calculations, and economic cybernetics research. 


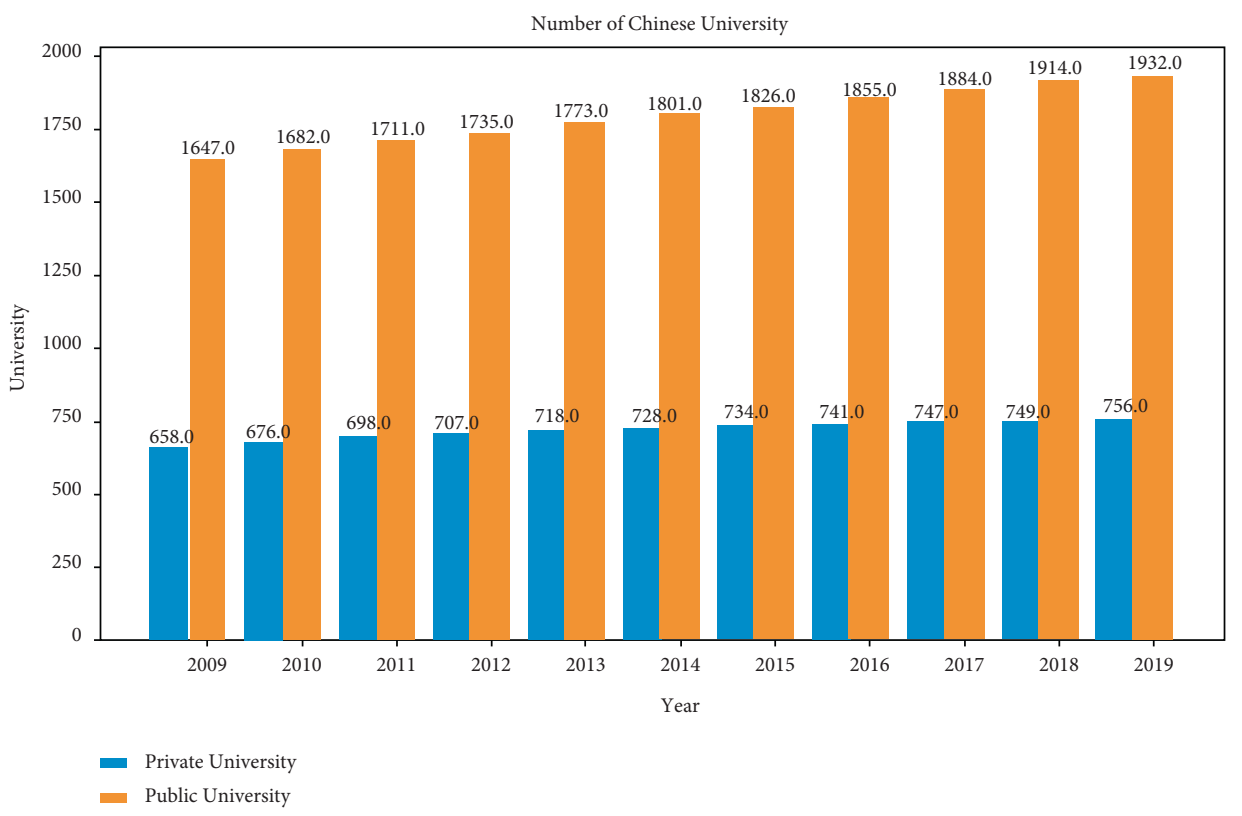

Figure 1: The number of Chinese public universities and private universities. Note: the data are from the website of the Chinese National Statistical Bureau: http://www.stats.gov.cn/.

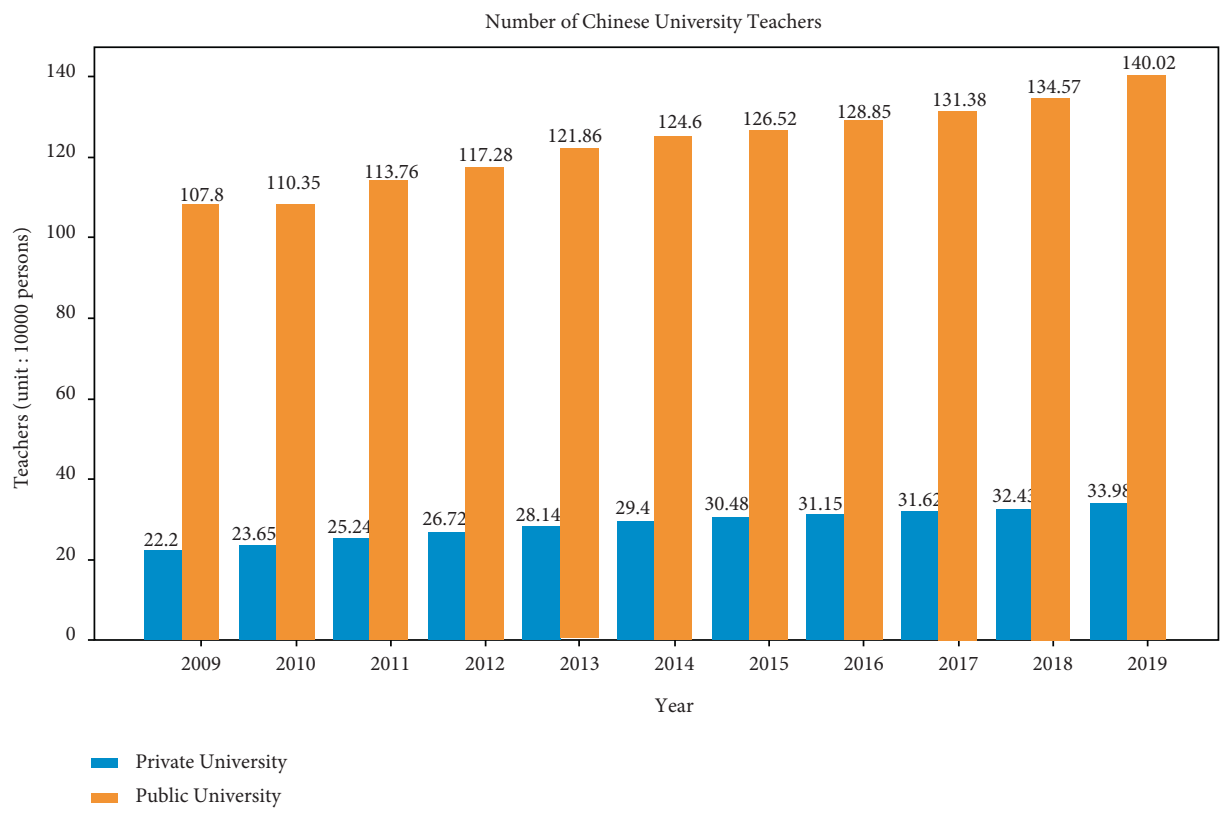

Figure 2: The number of Chinese public university teachers and private university teachers. Note: the data are from the website of the Chinese National Statistical Bureau: http://www.stats.gov.cn/.

In the research on how income influences the subjective happiness, it can be found in the early [9] research on wealth and subjective happiness that people in rich countries are much happier than those in poor countries. In the same country, wealthy people are much happier than poor people. The data from a study conducted by the authors [10] about the influence of the income on subjective happiness in different countries suggest that subjective well-being for people in rich countries outweighs those for people in poor countries. It also finds that for people from an unequal country, the impact of the income on the subjective happiness is higher than that from an equal country. Neman [11] carried out a study which shows that the income and income gap will influence the family's subjective happiness, and the influence degrees will be varied in different regions. Syrén et al. [12] found that the monthly total income for people with age from 42 to 50 is positively related to the subjective happiness, and the marginal effect of the income also relies on the character traits. Jiawen Ding et al. [13] took China as the example and had a research on how income inequality influences subjective happiness. Its result indicates that the absolute income and the relative income will 
influence the subjective happiness of the subject, and there is a subverted U-shape relationship among the urban residents between income inequality and the personal subjective happiness, while in rural regions, this relationship is always negative. Therefore, the income is an important factor influencing the subjective happiness. In many current research studies on university governance, for example, Mekvabidze [14] studied the optimal decision-making at the modern university level. Petrenko et al. [15] studied the relationship between entrepreneurial education and entrepreneurial achievements in underdeveloped countries. In the research aiming at the subjective happiness of teachers, Pretsch et al. [16] researched on inferring the subjective happiness of teachers from the details of the nonverbal information such as daily behaviors. Chen [17] researched on the factors of influencing the subjective happiness of teachers aiming at the underdeveloped regions of China. The findings are that those factors, including health, income, interpersonal relationship, personal value, leisure life, family life, and social status, will bring significant impact on the subjective happiness of teachers and the specific aspects of psychological influence on the physical and emotional health and why some aspects are not influenced.

The results showed that psychological interventions promote physical awareness and practice the need for selfcare, which exerts an evident influence on subjective wellbeing. Skaalvik and Skaalvik [18] found that job demand variables strongly predicted lower subjective well-being of teachers, while job resources moderately predicted higher subjective well-being of teachers. The subjective happiness of teachers will in turn predict higher devotion to work and lower resignation motive. Skaalvik and Skaalvik [18] believed that the subjective happiness of the teachers is related to their classroom practice and students' performance. Teacher mindfulness was significantly associated with lower levels of job stress, job burnout, depression, and anxiety symptoms. Job burnout was negatively correlated with observers' ratings of emotional support and classroom organization. Schwarzer et al. [19] researched on the psychological ability of teachers and found that whatever it is psychological symptoms load and subjective pressure, it will have a positive influence on the subjective happiness. In the study of the impact of the welfare system on employees, Ikechukwu [20] studied the organizational performance evaluation of private manufacturing companies: the impact of supply chain management responsiveness. Veingerl Cic et al. [21] applied the structural equation model to study the personal job performance management model. Dragic and Sorak [22] simulated how to improve the performance of SMEs.

In conclusion, in the study of income influencing subjective happiness, the focus of the current literature is the influence of income factor on the nonteacher group. In the study of teachers' subjective happiness, the influence of income on the teachers' subjective happiness is less involved, especially the research on whether income will influence and how it influences the subjective happiness of teachers in private universities. Aimed at Chinese private universities, the influence of income on the subjective happiness is researched in the paper. First of all, the features of the Chinese private universities are considered; the measuring model of subjective happiness of teachers is established, and then data are collected through staffing; at last, the structural equation model is used to research the influence of income on the teachers' subjective happiness in this paper. The research is theoretical and practical, for example, researching on the subjective happiness of teachers in private universities and providing the suggestions to enhance the teacher's subjective happiness in private universities.

\section{Base Model}

According to Li's research [3], subjective happiness is an important comprehensive psychological indicator for evaluating people's lives and it will greatly affect teachers' life and work. Accordingly, their teaching quality will be hindered by the subjective happiness.

2.1. Model Construction. According to the research of Syren et al. [12], Yue et al. [23], and Xing et al. [24], there is a significant relationship among the income, welfare system, and subjective well-being. The research framework and hypotheses in Figure 3 are proposed for teachers in private universities in China.

Meanwhile, the assumptions will be proposed:

$\mathrm{H} 1$ : income has a significant influence on the subjective happiness of private university teachers

H2: The welfare system of investor has a significant influence on income

H3: The welfare system of investor has a significant influence on the subjective happiness of private university teachers

2.2. Scale Design and Investigation Scheme. Scale is divided into two parts. The first part is the personal basic information, such as age, title, and education; the second one is measure of income taking salary, welfare status, housing status, and consumption level as observational variable and observation of the investor's welfare system based on observational variable in fund use system management culture and enterprise dividend. With reference to the methods in the quantifying method in the Likert scale, every problem is answered with subject to 5 grade attitudes: very satisfactory, satisfactory, average, poor, and unsatisfactory, and the corresponding score is 5, 4, 3, 2, and 1 as shown in Table 1 specifically.

According to the ratio among the number of universities in different regions of China, the questionnaire has been handed out to 21 private universities, including 6 universities in East China region, 5 universities in North China region, 5 universities in Southwest region, 3 universities in Northwest region, and 2 universities in Northeast region; totally 600 , 561 of which are collected, and the recovering rate reached 93.5\%. 


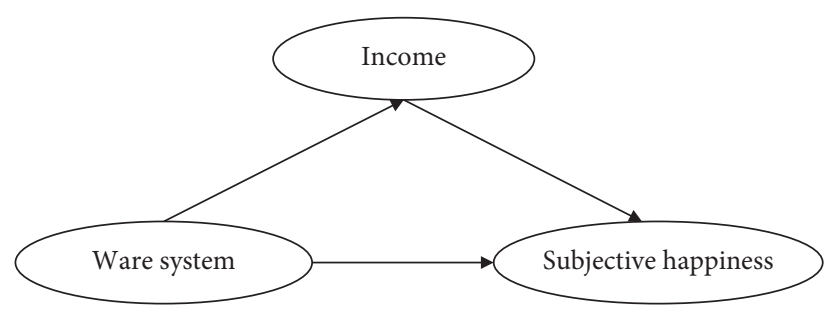

FIGURE 3: Research framework.

\section{Date Handling and Result Analysis}

3.1. Validity and Reliability Analysis. For investigation data, first we will carry out the validity test, and the results are as shown in Table 2. The clone Bach Alpha value of the income and investor is greater than 0.9, and the clone Bach Alpha value of the overall scale is greater than 0.9 , indicating that the validity is of high quality and can be analyzed further.

For the reliability test, the results are indicated in Table 3. From Table 3, we can see that the KMO value is 0.912 , which is greater than 0.5 . The significance of Bartlett's test of sphericity, $P=0$, was significant, indicating that the scale was suitable for factor analysis.

3.2. Variable Definition and Description Statistics. The teachers interviewed are mainly young teachers, with more male teachers and fewer female teachers. The number of teachers in liberal arts majors is equal to that of science and engineering majors, and the working years of these teachers are less than 3 years. The academic qualifications and professional titles of teachers in private colleges are generally low, and doctoral students and senior professional titles account for a relatively small proportion.

According to the investigation results in Figure 4, there are $44.39 \%$ people being interviewed felt averagely happy; $40.64 \%$ people felt relatively happy or very happy; and only 14.98 people felt unhappy or very unhappy. Therefore, the overall subjective happiness of Chinese private university teachers is good, but there are fewer people who think they are very happy.

As for the investigation on the income and welfare system, the average value of all observational variables is between 2.5 and 3. Among them, they are most unsatisfied with enterprise development dividend and are most satisfied with housing conditions, which is shown in Table 4 in detail.

3.3. Assumption Test. The analysis of assumption test result is shown in Table 5. It shows that the income has a significant impact on the subjective happiness of Chinese private universities teachers. Investor has greatly influenced the income of Chinese private universities teachers. Investor has a huge impact on the subjective happiness of Chinese private universities teachers.

3.4. Factor Analysis. To figure out the influence degree and mode of income on the subjective happiness of Chinese
TABLE 1: Indicator evaluation table.

\begin{tabular}{lccccc}
\hline Grade & $\begin{array}{c}\text { Very } \\
\text { satisfactory }\end{array}$ & Satisfactory & Average & Poor & Unsatisfactory \\
\hline 5 & 5 & 4 & 3 & 2 & 1 \\
scale & 5 & & & & \\
\hline
\end{tabular}

TABLE 2: Validity analysis.

\begin{tabular}{lcc}
\hline Measuring variable & Clone Bach Alpha & Item number \\
\hline Income & 0.913 & 4 \\
Investor & 0.957 & 3 \\
Overall scale & 0.946 & 7 \\
\hline
\end{tabular}

TABle 3: KMO and Bartlett test.

\begin{tabular}{lcc}
\hline $\begin{array}{l}\text { KMO measure of sampling } \\
\text { adequacy }\end{array}$ & 0.912 \\
\hline Bartlett's test of sphericity & $\begin{array}{c}\text { Approx. chi- } \\
\text { square }\end{array}$ & 4029.557 \\
& $\begin{array}{c}\text { Freedom degree } \\
\text { Significance }\end{array}$ & $\begin{array}{c}21 \\
0.000\end{array}$ \\
\hline
\end{tabular}

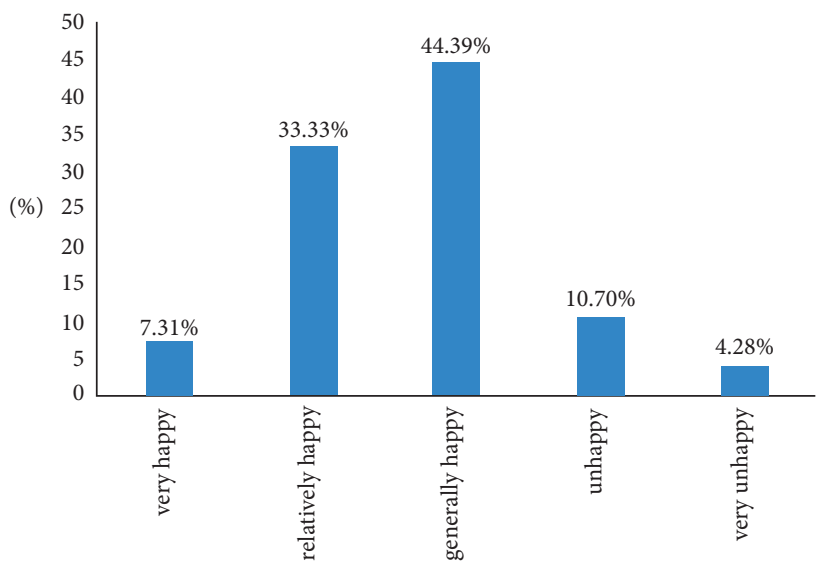

FIGURE 4: Statistics of subjective happiness.

private universities as well as investor on the Chinese private universities, factors analysis is as follows.

First of all, Figure 5 shows the fitting index of the whole model. The GFI (goodness-of-fit index) and AGFI (adjusted 
TABLE 4: Variable definition and score statistics.

\begin{tabular}{|c|c|c|c|}
\hline Variable symbol & Variable definition & Average value & Standard deviation \\
\hline CD5_1 & Salary income & 2.606 & 1.045 \\
\hline CD5_2 & Satisfaction to housing condition & 2.959 & 1.004 \\
\hline CD5_3 & Satisfaction to social welfare & 2.677 & 1.046 \\
\hline CD5_4 & Satisfaction to current consumption level & 2.781 & 0.978 \\
\hline CD6_1 & Satisfaction to the expenditure system of investor & 2.681 & 1.044 \\
\hline CD6_2 & Satisfaction to management culture of investor & 2.706 & 1.046 \\
\hline CD6_3 & Satisfaction to enterprise development dividend of the investor & 2.510 & 1.081 \\
\hline
\end{tabular}

TABle 5: Assumption test result analysis.

\begin{tabular}{|c|c|c|c|c|}
\hline Assumption & $\begin{array}{c}\text { Standard route } \\
\text { coefficient }\end{array}$ & $Z$ value & $P$ & Conclusion \\
\hline $\begin{array}{l}\text { H1: income has a significant impact on the subjective happiness of Chinese private } \\
\text { universities teachers }\end{array}$ & 0.463 & 5.892 & $\leq 0.001$ & Significant \\
\hline $\begin{array}{l}\text { H2: investor has a significant impact on the income of Chinese private universities } \\
\text { teachers }\end{array}$ & 0.834 & 23.709 & $\leq 0.001$ & Significant \\
\hline $\begin{array}{l}\text { H3: investor has a significant impact on the subjective happiness of Chinese private } \\
\text { universities teachers }\end{array}$ & 0.532 & 9.426 & $\leq 0.001$ & Significant \\
\hline
\end{tabular}

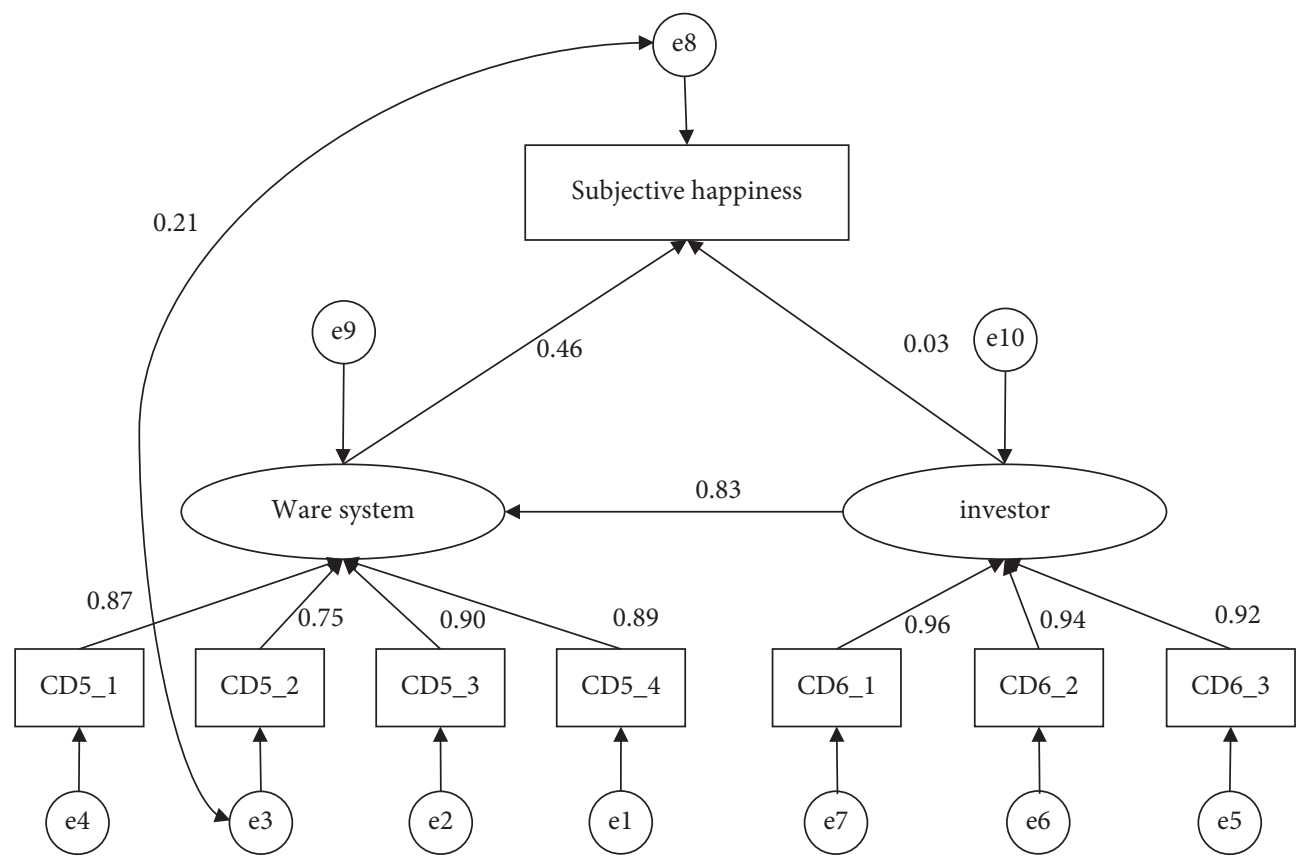

FIGURE 5: Structural equation model analysis.

goodness-of-fit index) are all above 0.9, the CFI (comparative fit index) and TLI (Tucker-Lewis index) are all above 0.9 , and the RMSEA (root mean square error) is less than 0.8 . Based on these indexes, the results indicate that the fittings of the data to the structural equation model are good.

Second, the maximum likelihood method is adopted to verify the proposed assumption. In Table 6 , the result of the variance violation estimation test on the model is shown. From Table 6, all error variances in the model are all greater than 0 , which proves there is no outlier. All error variances are significant, which means that every error variance does exist. At the same time, there is no great standard error (SE), which indicates that this model does not violate estimation.
TABLE 6: Variance violate estimation test result.

\begin{tabular}{lcccc}
\hline & Estimation & S.E. & C.R. & $P$ \\
\hline e10 & 0.984 & 0.069 & 14.185 & $\leq 0.001$ \\
e9 & 0.228 & 0.021 & 10.953 & $\leq 0.001$ \\
e8 & 0.624 & 0.038 & 16.307 & $\leq 0.001$ \\
\hline
\end{tabular}

Therefore, it can be concluded that the measuring indicator proposed in this model is reasonable.

Finally, the output route analysis is shown in Figure 5. The average path coefficient between welfare status and four factors (i.e., income, consumption level, welfare status, and housing condition) is 0.85 , indicating that the latter is better 
for welfare situation. The best explanatory factor is social welfare, with a path coefficient of 0.90 , while the worst is housing condition with a path coefficient of 0.75 . The path coefficients of investors and the other three factors, namely, funding system, corporate culture, and enterprise development dividend, are 0.96, 0.94, and 0.92, respectively, which illustrates that these three factors can explain welfare status greatly.

\section{Conclusion}

According to the result of this model, based on features of Chinese private universities, we can reach the following conclusions.

First, in the light of adjustment variable analysis, major and professional title have obvious influence on subjective happiness of teachers, while gender, educational background, and age have less impact on teachers' subjective well-being. After multiple comparisons, it is found that there is distinct difference between the subjective happiness of assistants and lecturers. Subjective happiness of lecturers is higher than that of teaching assistants. And the higher the professional title is, the stronger the subjective happiness will be. Therefore, it is suggested to provide more study and training opportunities, helping teachers to improve themselves. A fair promotion system of professional title should be improved, so as to increase teachers' objective happiness. Furthermore, there are obvious differences between the subjective happiness of unmarried and married teachers since subjective happiness of the married is higher. There is also significant difference between the subjective happiness of liberal arts and science teachers. Science teachers can gain the top well-being, followed by those of engineering and liberal arts teachers. Therefore, it is recommended that we should enhance our cooperation and exchanges among teachers in varied majors and encourage trans-professional cooperation in teaching and scientific research, thereby increasing their subjective happiness by influential ways.

Second, the subjective well-being of teachers in Chinese current private universities still continues well but the proportion of teachers in great happiness remains relatively low. The welfare status and salary will affect their overall income because it has significantly positive impact on their subjective happiness through consumption level and housing condition. Therefore, it is suggested to take measures to increase their income by encouraging and supporting teachers' endeavor in scientific research, social services, and other aspects, further elevating their subjective well-being. In China, the gap welfare status between private and public universities directly affects teachers' subjective happiness. However, they generally provide teachers dormitory and welfare housing, so housing condition has the worst explanatory effect on teachers' subjective well-being.

At last, the welfare system of investor has a significant impact on teachers' income. It will not only indirectly affect subjective happiness through income but also directly hamper them through the welfare system. Based on the management structure of Chinese private universities, private universities operating fees are mainly from investors so that the welfare system has a significantly positive influence on teachers' income. Therefore, it is recommended that investors should establish a more humanized and suitable welfare system for private universities to improve teachers' subjective happiness.

\section{Data Availability}

The data that support the finding of this study are available from the corresponding author upon reasonable request.

\section{Conflicts of Interest}

The authors declare that they have no conflicts of interest.

\section{References}

[1] A. Campbell, P. E. Converse, and W. L. Rodgers, "The Quality of American Life: Perceptions," Evaluations, and Satisfactions, Russell Sage Foundation, New York. NY, USA, 1976.

[2] E. Diener, "Subjective well-being," Psychological Bulletin, vol. 95, no. 3, pp. 542-575, 1984.

[3] Y. Li, "The research development on subjective well-being," Tian Jin Normal University Journal, vol. 33, no. 2, pp. 70-74, 2006.

[4] S. Li, Y. Chen, and G. He, "Laugh and grow fat: happiness affects body mass index among Urban Chinese adults," Social Science and Medicine, vol. 208, pp. 55-63, 2018.

[5] F. A. Ogedengbe, "Management of educational organization: the effectiveness of soft skill on rejuvenating education curriculum," Journal of Logistics, Informatics and Service Science, vol. 6, no. 1, pp. 15-37, 2021.

[6] S. W. Ju and L. S. Jung, "Experience satisfaction and buying intention of exhibition experience: an empirical study," Journal of System and Management Sciences, vol. 10, no. 1, pp. 72-82, 2020.

[7] S. M. Suldo, A. Thalji-Raitano, M. Hasemeyer, C. D. Gelley, and B. Hoy, "Understanding middle school students' life satisfaction: does school climate matter?" Applied Research in Quality of Life, vol. 8, pp. 169-182, 2013.

[8] F. Georgescu, B. Cozmanca, A. M. Cazacu, and A. M. Cojocaru, "Fiscal and income incentives trigger imbalances in a partly functional market economy," Economic Computation and Economic Cybernetics Studies \& Research, vol. 54, no. 2, pp. 5-22, 2020.

[9] E. Diener and R. Biswas-Diener, "Will money increase subjective well-being?" Social Indicators Research, vol. 57, no. 2, pp. 119-169, 2002.

[10] W. Ng and E. Diener, "Affluence and subjective well-being: does income inequality moderate their associations?" Applied Research in Quality of Life, vol. 14, no. 1, pp. 155-170, 2019.

[11] T. S. Neman, "Does your neighborhood's income distribution matter? A multi-scale study of financial well-being in the U.S," Social Indicators Research, vol. 152, no. 3, pp. 951-970, 2020.

[12] S. M. Syrén, K. Kokko, L. Pulkkinen, and J. Pehkonen, "Income and mental well-being: personality traits as moderators," Journal of Happiness Studies, vol. 21, pp. 547-571, 2020.

[13] J. Ding, J. Salinas-Jiménez, and M. d. M. Salinas-Jiménez, “The impact of income inequality on subjective well-being: the case of China," Journal of Happiness Studies, vol. 22, pp. 845-866, 2021.

[14] R. Mekvabidze, "From business modeling to business management: an exploratory study of the optimal decision making 
on the modern university level," Journal of Logistics, Informatics and Service Science, vol. 7, no. 1, pp. 67-86, 2020.

[15] Y. Petrenko, O. Masood, K. Javaria, E. Vechkinzova, and V. Elena, "Entrepreneurship education and startups: a case study of less developed countries," Journal of System and Management Sciences, vol. 9, no. 4, pp. 39-49, 2019.

[16] J. Pretsch, B. Flunger, N. Heckmann, and M. Schmitt, "Done in 60s? Inferring teachers' subjective well-being from thin slices of nonverbal behavior," Social Psychology of Education, vol. 16, pp. 421-434, 2013.

[17] Y. L. Chen, Study on the Subjective Happiness of College Teachers in Underdeveloped Areas during the Social Transformation Period, Lanzhou University, Lanzhou, China, 2015.

[18] E. M. Skaalvik and S. Skaalvik, "Job demands and job resources as predictors of teacher motivation and well-being," Social Psychology of Education, vol. 21, pp. 1251-1275, 2018.

[19] N. H. Schwarzer, T. Nolte, P. Fonagy, J. Griem, U. Kieschke, and S. Gingelmaier, "The relationship between global distress, mentalizing and well-being in a German teacher sample," Current Psychology, 2021.

[20] A. J. Ikechukwu, "Assessment of organizational performance of private manufacturing companies: the impact of supply chain management responsiveness," Journal of System and Management Sciences, vol. 9, no. 3, pp. 26-44, 2019.

[21] Z. Veingerl Cic, N. V. Herzog, and A. Macek, "Individual work performance management model," International Journal of Simulation Modelling, vol. 19, no. 1, pp. 112-122, 2020.

[22] M. Dragic and M. Sorak, "Simulation for improving the performance of small and medium sized enterprises," International Journal of Simulation Modelling, vol. 15, no. 4, pp. 597-610, 2016.

[23] J. L. Yue and K. Fang, "Welfare stratification: China's income inequality in the view of social policy," Social Science Research, vol. 1, pp. 115-124, 2020.

[24] Z. J. Xing and L. Chu, "The well-being research and its enlightenment from the perspective of welfare state," Dongyue Tribune, vol. 3, pp. 50-56, 2020. 